\title{
Thorium Fuel Cycle Activities in IAEA
}

\author{
Uddharan Basak
}

The Nuclear Fuel Cycle and Materials Section of the International Atomic Energy Agency (IAEA) organizes technical meetings and symposia, facilitates technical cooperation, coordinates research projects, prepares state of the art technical documents and maintains and updates databases on nuclear fuels and fuel cycles. The IAEA conducts a programme on "Advanced Nuclear Fuels and Fuel Cycle Options", in particular, on the thorium fuel cycle, for which the main incentives and challenges are well known.

Thorium-based fuels have been studied for their potential applications in almost all types of reactors including water reactors (WRs), boiling water reactors (BWRs), pressurized heavy water reactors (PHWRs), high-temperature reactors (HTRs), fast breeder reactors (FBRs) and molten salt reactors (MSR), though on a small scale compared with U/U-Pu fuels. The motivation for developing thorium technologies are: utilization of the large energy potential of thorium resources, transuranic actinide $(\mathrm{Pu}$ and/or minor actinides (MAs)) consumption/management and a proliferation resistant fuel cycle. Sustainable development of nuclear energy is possible through the deployment of the thorium fuel cycle.

During the period 2011-2013, IAEA technical meetings were held on world thorium resources, on fuel integrity during normal operating and accidental conditions in PHWR and on advanced fuel cycles in PHWRs.

During the period 2012-2015, Coordinated Research Activities (CRP) have progressed on "near-term and promising long-term options for deployment of thoriumbased nuclear energy". Participating Member States are Canada, China, Czech Republic, Germany, Italy, Israel, India, Russian Federation, UK and USA. Preliminary neutronic analysis shows that thorium enables sustained transuranics burning in all reactor systems analyzed: reduced-moderation pressurized water reactors (RMPWRs), reduced-moderation boiling water reactors (RMBWRs) and fast reactors (FRs). Furthermore, an investigation indicates that using the Th/U-233 fuel cycle in HTR-PM (pebble module) is feasible and realistic. A new CRP was launched on the "reliability of high-power, extended burnup and advanced PHWR fuels (2013-2017)". IAEA publications on the thorium fuel cycle and documents on world thorium resources can be found at http://infcis.iaea.org.

In summary, the use of thorium-based fuels was demonstrated in almost all types of reactors during the period between the 1960s and the mid-1980s. Large resources of thorium, along with favorable waste management and intrinsic proliferation characteristics of the thorium-uranium fuel cycle, instill the potential for the sustainable development of nuclear energy. Technological challenges remain for remote and automated processes even for the front end of the thorium-uranium fuel cycle in well-shielded facilities. Global attitudes towards deployment of the thorium fuel cycle are fast changing.

U. Basak $(\bowtie)$

Nuclear Fuel Cycle and Materials Section, Division of Nuclear Fuel Cycle and Waste Technology, Department of Nuclear Energy, International Atomic Energy Agency (IAEA), Vienna, Austria 